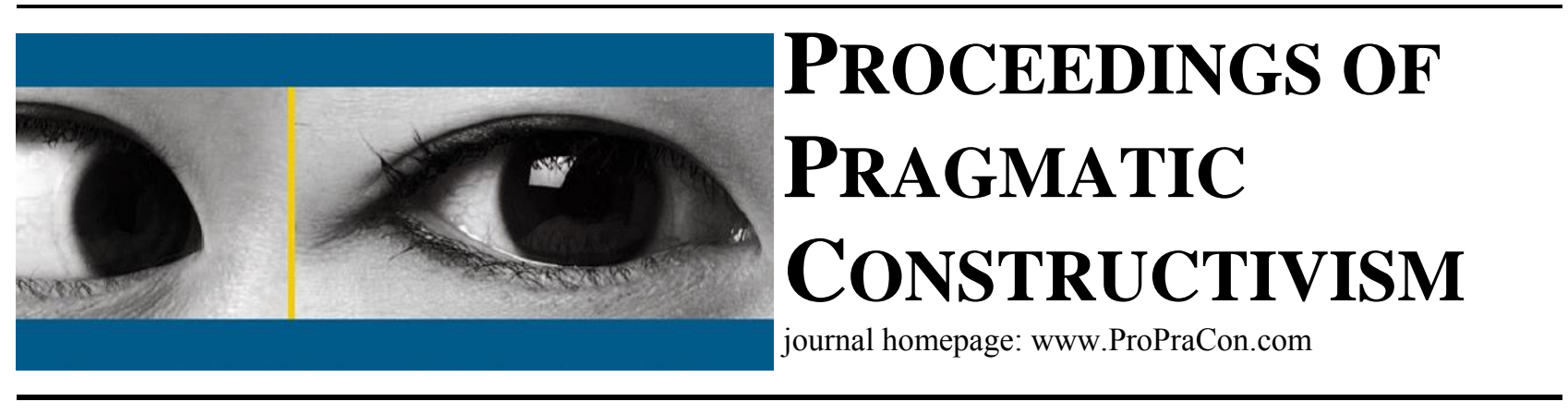

\title{
When prices for land lost its grounding and management accounting was set-aside
}

Morten Jakobsen

Associate Professor of Management Accounting and Control

Aarhus University; School of Business and Social Sciences; Department of Economics and Business

Fuglesangs Allé 4, 8210 Aarhus V, Denmark; mja@asb.dk

\section{Abstract}

This study addresses the current situation in the Danish agricultural sector when prices for land lost its grounding and management accounting was set-aside.

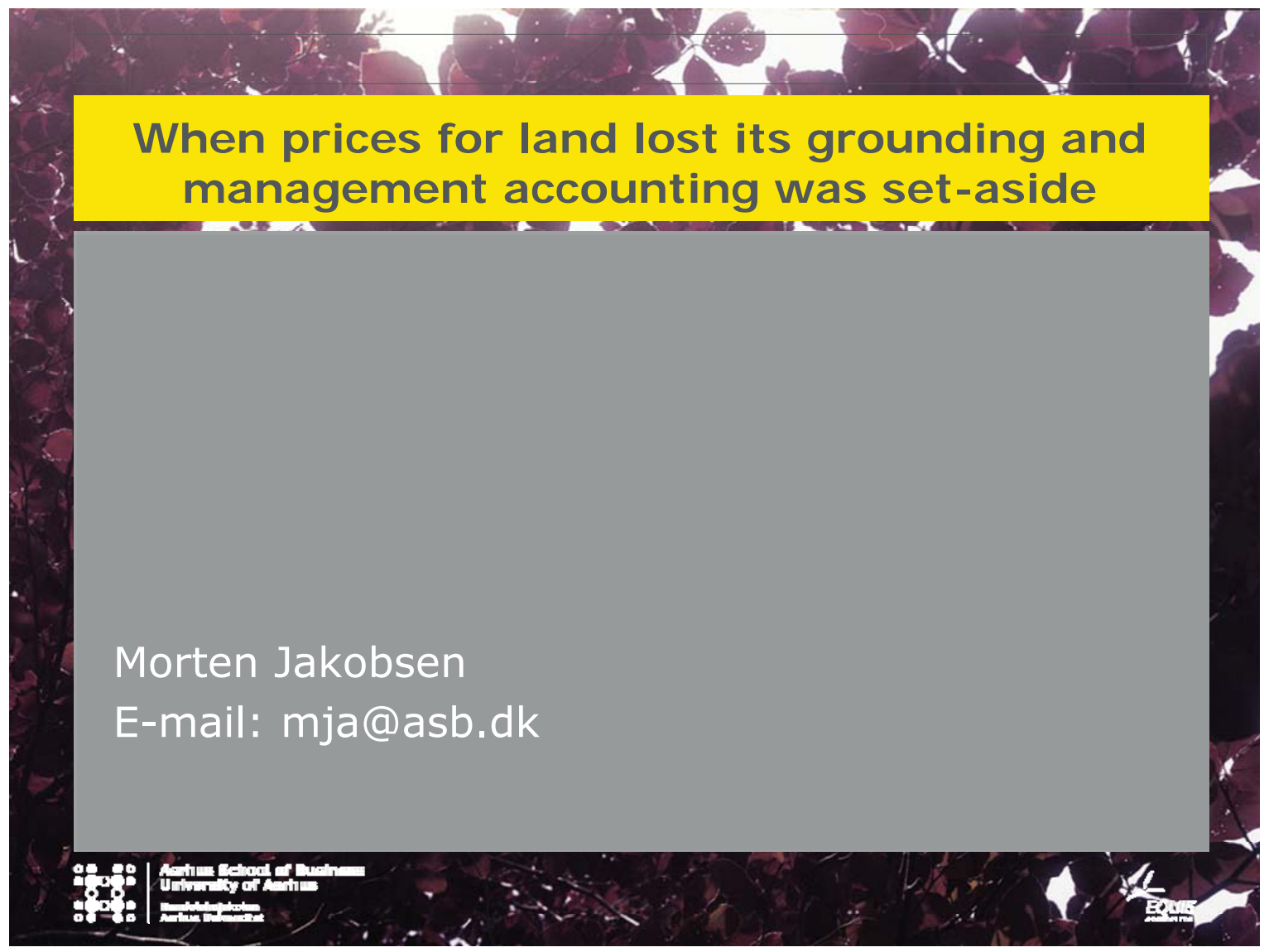




\section{Agenda}

- Some background information on the Danish Agricultural sector

- Objective and research questions

- Methodology

- Findings and implications

\section{Some background information}

- Historically low profit industry.

- The industry is capital intensive, huge investments in land, buildings and live stock compared to present turnover.

- Asset turnover 0.31 in 1991, 0.09 in 2009, for an average fulltime holding. Manufacturing companies in Denmark AT > 1.0

- Easy access to debt financing:

- Up to 70 percent financing by mortgage banks

- Nearly the rest financed by banks

- For young farmers equity often $<0$ within the first year 


\section{Some accounting information from an "average" farm holding}

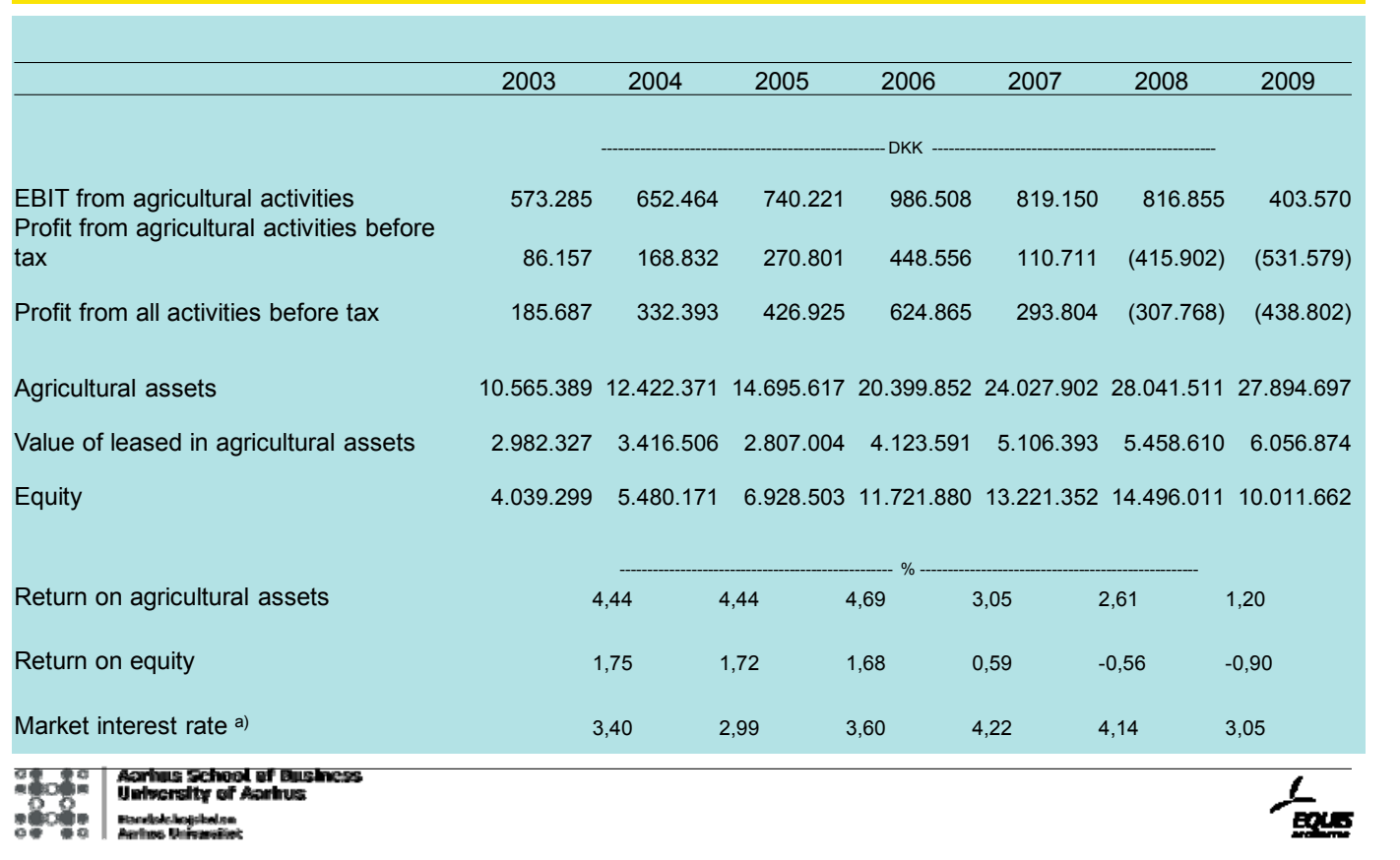

\section{Development in real prices}

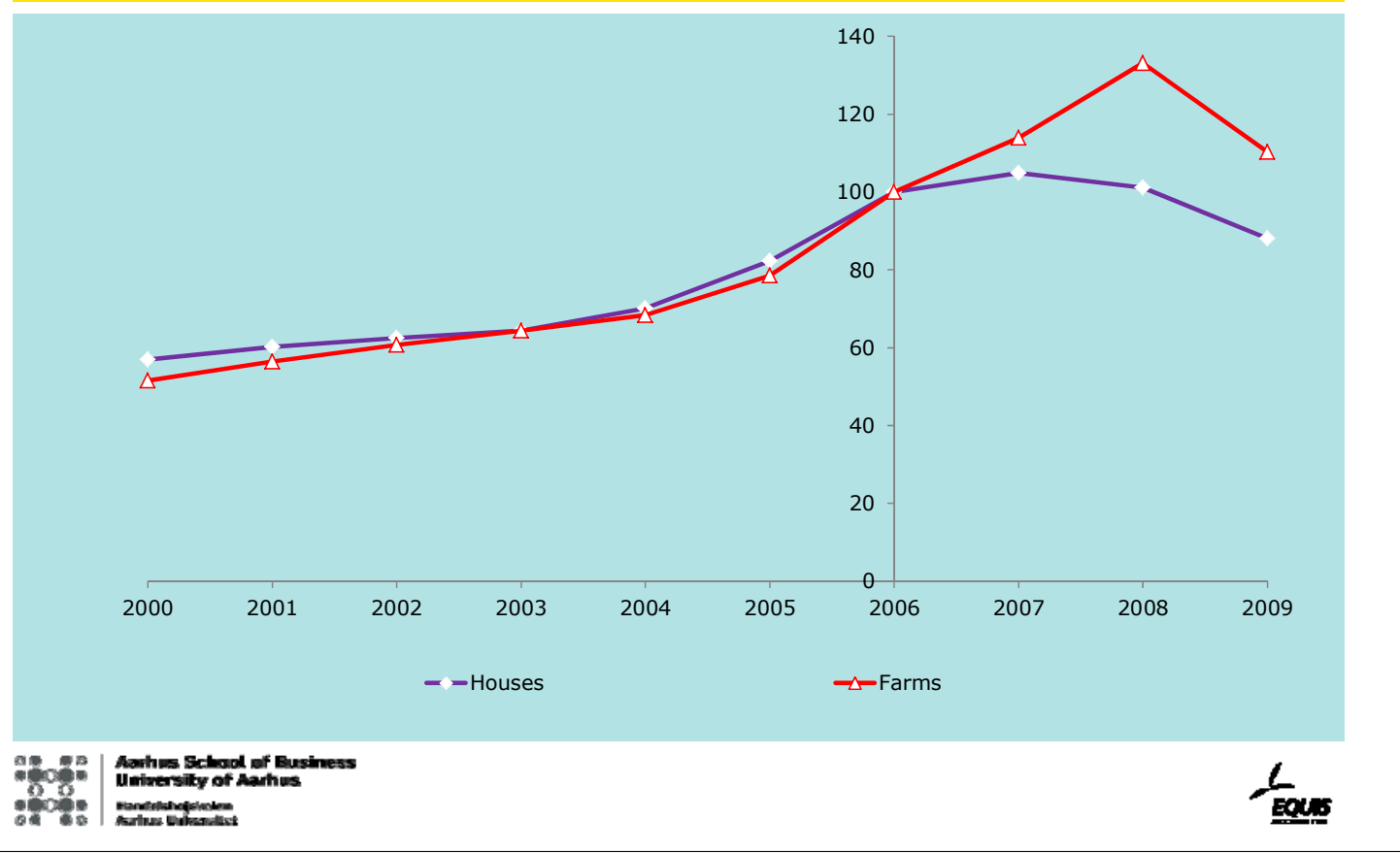




\section{Objective and research questions}

- Economic rationale cannot justify the price increases seen on the aggregated level within the agricultural sector.

- An entire sector seems to be in u-topos

- The objective of this paper is to expose causes that have led to the economic bobble in the Danish agricultural sector and left this industry in a huge crisis.

- Research questions:

- What are the farmers' motives for engaging in investments that does not generate an economic profit?

- What role have the agricultural advisors taken during the decision processes that have led to the present situation?

- Why have financial institutions financed investments in the agricultural sector that is obviously unprofitable?

\section{Methodology}

- The study is based on a qualitative case study that includes semi structured interviews with:

- bank managers and staff in agriculture departments in two banks located in two different areas of Denmark.

- In one of these areas three farmers were interviewed individually, and in the other area 8 farmers participated in a focus group interview.

- In each of the two areas one agricultural consultant was also interviewed.

- All interviews was recorded and transcribed for further analysis.

- The data is analysed by using the pragmatic constructivist framework 


\section{Methodology}

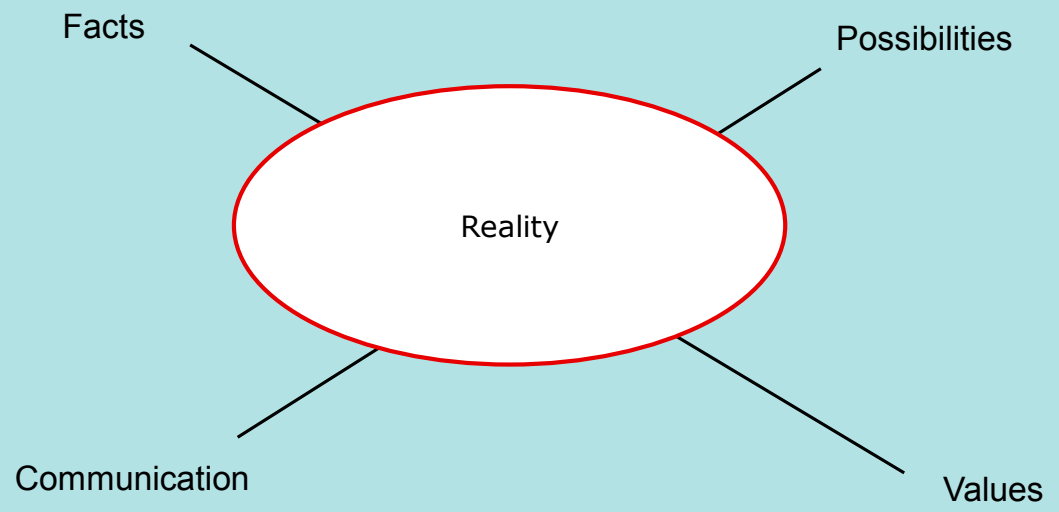

\section{Facts}

- They are extremely focussed on the concrete phenomena of their business

- The phenomena are made manageable via non-financial performance measures

- The credit draft account is a central yardstick for financial control.

- Other financial performance measures are not used in the managerial decision process, except for communication with banks.

- The coupling between accounting numbers and concrete phenomena are found too abstract 


\section{Values}

- Being a farmer is a deep rooted part of their identity and selfperception

- They enjoy showing you their holdings and possessions, but they would never dream of revealing last years profit

- They are extreme optimists

- They have a true believe in economies of scale and general increases in efficiency as the way to solve decreasing terms of trade

- What counts is size - to grow is the most important success factor

- They run "cigar-box" financial control if there is an opportunity to grow and it can be financed, then they go for it.

\section{Communication}

- Three main groups of actors:

- Financial institutions

- Farmer's association

- Farm consultants (owned by the farmer's associations)

- The remaining society is a hindrance - they ask too many questions that are difficult to answer'. Relatively low degree of communication 


\section{Communication}

- Communication with Financial institutions are made via budgets and annual accounts

- Unequal communication, the farmer delivers information, that is often produced by his advisor, and the bank decides for further lending on that basis.

- If the bank says go then the farmers perceives this as a confirmation of the rightness in the decision

- Until 2008 banks never said no $\rightarrow$ growth was beyond dispute

- Such practice was by the farmers perceived as an accept and a reward for setting management accounting aside.

\section{Communication}

- Agricultural advisors work are employed by the farmers via the farmers' association.

- As a result of structural changes, the advisors has become profit centres.

- The single farmer is now the customer who should be given what he asks for - no critical voice.

- The farmers have low trust in the advisors. Therefore the advisors are mainly used for administrative tasks. 


\section{Possibilities}

- The farmers see growth in volume as the only possibility to develop their business

- Their main focus on non-performance indicators supports this strategy: more milk per cow, more piglets per sow, etc. (at any price)

- And when possible: more animals, more land, etc. (at any price)

- Since accounting logic is set-aside there is no attention pointed at alternatives.

- Advisors are reduced to clerks

- The surrounding society is out of reach, they only talk about environmental care and organic farming

\section{:80:}

\section{I mplications}

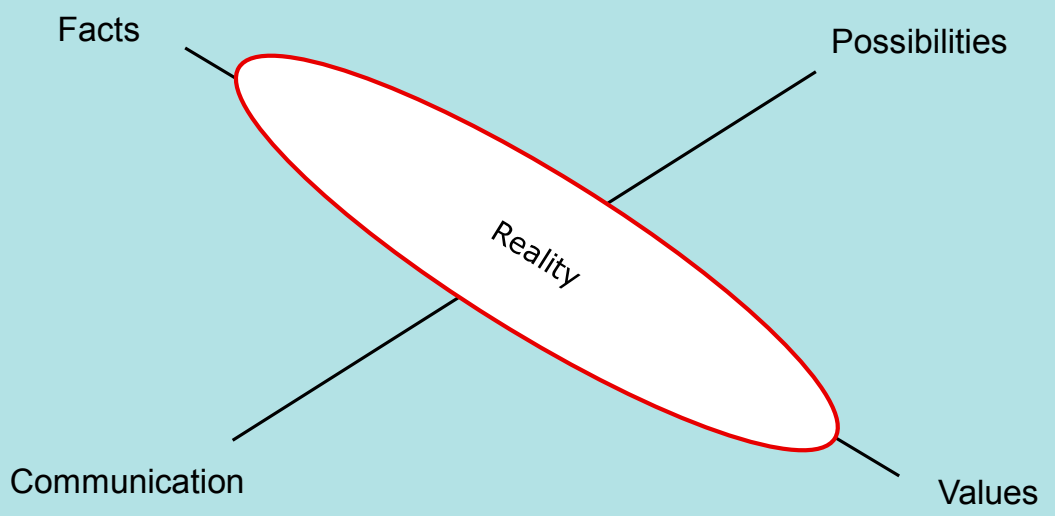




\section{I mplications}

- Based on this extreme case !

- Non-financial performance measures has one directional attention: more is better or less is better.

- Good for revenue or cost

- But no automatic focus on profit.

- Thereby the actions of actors might harm the overall performance of the company

- The logic of economics and accounting is cost vs. Benefits

- Automatic balanced focus.

- But on a more abstract level because actions of actors have been translated into monetary units

\section{Questions and comments}

